\title{
Videoangiografia digital com a fluoresceína sódica e indo- cianina verde na doença hipertensiva específica da gestação
}

\author{
Digital fluorescein and indocyanine green videoangiography in pregnancy toxemia
}

\author{
Maurício B. Pereira ${ }^{(1)}$ \\ Juliana Ferraz Salum (2) \\ Daniela Calucci ${ }^{(3)}$ \\ Paulo Eduardo Ferraz ${ }^{(4)}$ \\ Fausto Uno ${ }^{(5)}$ \\ Michel E. Farah ${ }^{(6)}$
}

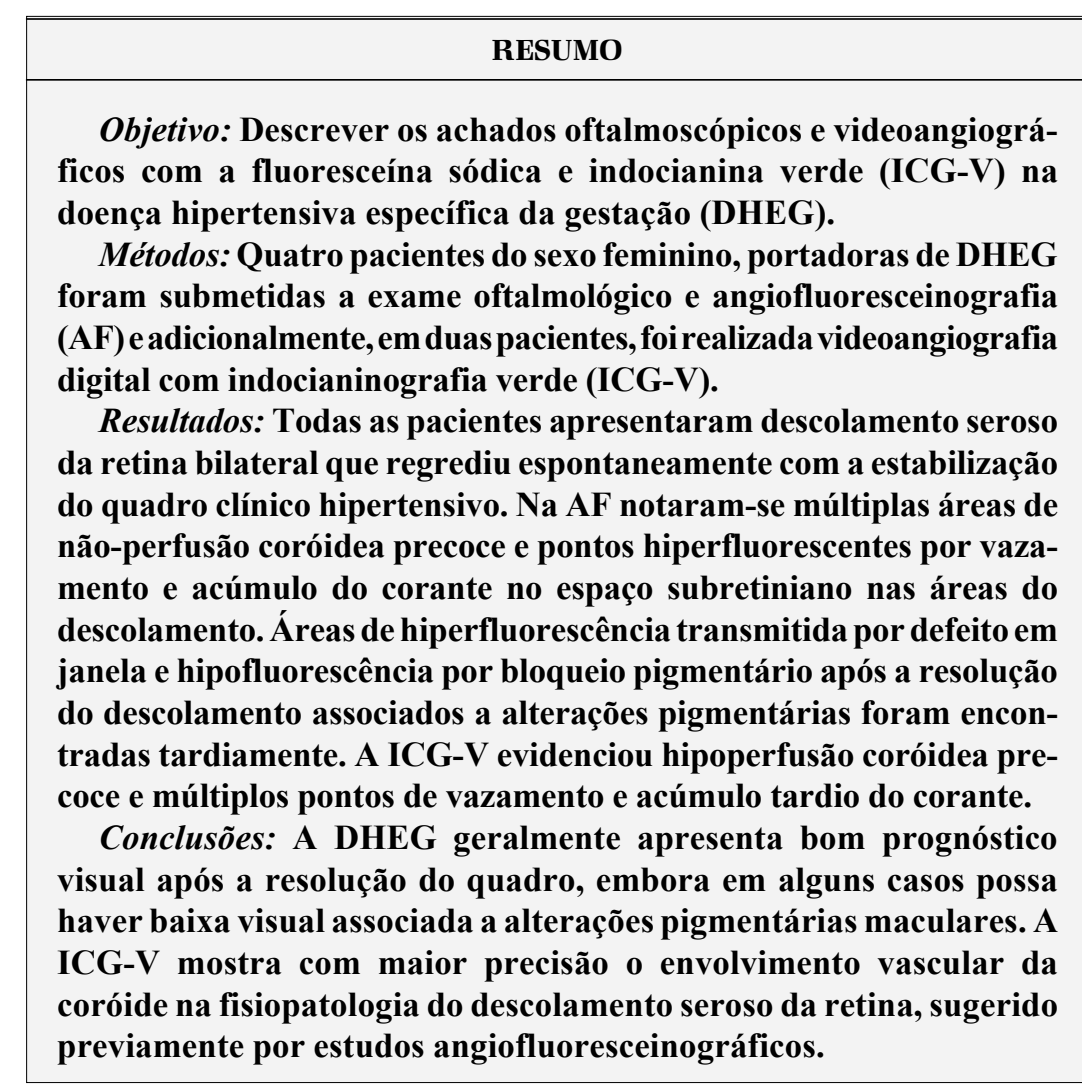

Palavras-chave: Doença hipertensiva específica da gestação; Aspectos fundoscópicos; Indocianina Verde; Angiofluoresceinografia.
Trabalho realizado no Setor de Retina e Vítreo do Departamento de Oftalmologia da Universidade Federal de São Paulo, UNIFESP, Escola Paulista de Medicina.

(1) Pós-graduando nível doutorado do Setor de Retina e Vítreo.

2) Pós-graduanda nível doutorado do Setor de Retina e Vítreo.

(3) Tecnóloga em oftalmologia

(4) Pós-graduando nível mestrado do Serviço de Ginecologia e Obstetrícia.

5) Mestre e chefe do Setor de Retina e Vítreo.

(6) Professor adjunto doutor e livre docente.

Os autores não têm interesse comercial nos produtos e equipamentos utilizados nesse estudo. Tema livre apresentado no XIII Congresso Brasileiro de Prevenção da Cegueira e Reabilitação Visual (setembro 1998) - Rio de Janeiro, RJ.

Endereço para correspondência: Maurício B. Pereira. Rua Fadel Fadel, 84/602. Rio de Janeiro (RJ) CEP 22430-170. e-mail: maubasp@uol.com.br

\section{INTRODUÇ̃̃OO}

A doença hipertensiva específica da gestação (DHEG) é uma das principais causas de morbidade e mortalidade materna ${ }^{1}$. Ela pode se manifestar de forma pura, sem antecedentes de hipertensão crônica, ou sobreposta a uma doença hipertensiva subjacente. Geralmente acomete primigestas com maior incidência em casos de gemelaridade e mola hidatiforme. $\mathrm{O}$ diagnóstico de DHEG se faz principalmente por volta da $24^{\mathrm{a}}$ semana de gestação, na presença da tríade clássica: hipertensão, edema e proteinúria ${ }^{2}$ é chamada de pré-eclâmpsia e, na presença de convulsões ou coma, de eclâmpsia ${ }^{3}$.

Entre 30 e $50 \%$ destas pacientes apresentam queixas visuais, variando de apenas discreto embaçamento visual até quadros de escotomas ou amaurose ${ }^{4}$.

Uma das alterações oftalmológicas raras é o descolamento seroso de retina, que pode se manifestar antes ou após o parto em cerca de $1 \%$ das 
gestantes com pré-eclâmpsia e $10 \%$ nos casos de eclâmpsia ${ }^{5,6}$. Estes descolamentos geralmente apresentam regressão espontânea, sem seqüelas visuais ${ }^{7}$.

\section{MATERIAL E MÉTODOS}

Apresentaremos os achados oftalmoscópicos e angiográficos de quatro pacientes portadoras da DHEG avaliadas pelo Setor de Retina e Vítreo do Departamento de Oftalmologia da Escola Paulista de Medicina/Universidade Federal de São Paulo correlacionando as alterações vasculares na retina e coróide com a fisiopatologia dessa doença. A avaliação angiográfica incluiu em 2 casos a realização da videoangiografia digital com indocianina verde (ICG-V) (Topcon IMAGEnet ${ }^{\circledR}$ 640/1024), 10 minutos após o término da angiofluoresceinografia (AF) com injeção "em bolo" de $25 \mathrm{mg}$ de indocianina verde diluídos em $2 \mathrm{ml}$ de solvente aquoso e as imagens foram obtidas até 30 minutos após a administração do corante.

\section{DESCRIÇÃO DOS CASOS CLÍNICOS}

\section{Paciente 1}

Gestante de 16 anos, branca, primigesta na $39^{\mathrm{a}}$ semana de gestação, iniciou trabalho de parto, seguido 3 horas após por diminuição súbita da visão, tonturas, perda da consciência e crise convulsiva. Ao exame apresentava edema de membros inferiores (MMII), proteinúria de $2+$ e pressão arterial (PA) de 190x115 mmHg. Com o diagnóstico de eclâmpsia, foram prescritos sulfato de magnésio e hidralazina e foi submetida a parto cesáreo com feto único vivo. Três dias após o parto foi encaminhada para avaliação oftalmológica apresentando $\mathrm{AV}$ de movimentos de mão em $\mathrm{AO}$, e na oftalmoscopia, alterações bilaterais caracterizadas por múltiplas áreas com lesões em placa branco-amareladas no pólo posterior e descolamento seroso extenso da retina bilateral com acometimento macular formando extensas bolsas periféricas (Figura 1A).

A AF mostrou múltiplas áreas de não perfusão placóide coróidea, inúmeros pontos hiperfluorescentes com vazamento e acúmulo tardio do corante no espaço subretiniano nas áreas de descolamento seroso (Figura 1C) em ambos os olhos. Na ICG-V notamos hipoperfusão coróidea precoce e várias áreas hiperfluorescentes com vazamento e acúmulo tardio do corante (Figura 1D).

Após quatro dias, houve resolução total do descolamento seroso da retina, persistindo alterações pigmentárias no pólo posterior com melhora progressiva da AV de 20/60 para 20/20 em AO após 2 meses.

\section{Paciente 2}

Gestante de 22 anos, branca, primigesta na $32^{\mathrm{a}}$ semana de gestação, com queixa de diminuição súbita da visão no OE há 2 dias. Apresentava edema generalizado e PA de 175x120
mmHg. Ao exame oftalmológico apresentava AV de 20/40 no OD e conta dedos a $30 \mathrm{~cm}$ no $\mathrm{OE}$ e, na oftalmoscopia, alterações bilaterais caracterizadas por múltiplas áreas com lesões em placa branco-amareladas no pólo posterior e descolamento seroso da retina com acometimento macular do OE. No OD havia uma lesão coriorretiniana cicatricial hiperpigmentada de um diâmetro papilar nasal inferior ao disco óptico. Foi realizado o diagnóstico de pré-eclâmpsia e prescrito tratamento com sulfato de magnésio e hidralazina e realizado parto cesáreo com feto único vivo e estabilização do quadro materno.

Foi submetida a AF apresentando múltiplas áreas de não perfusão placóide coróidea, inúmeros pontos hiperfluorescentes com vazamento e acúmulo tardio do corante no espaço subretiniano nas áreas de descolamento seroso em ambos os olhos. Sete dias após o parto, apresentou resolução do descolamento seroso da retina, persistindo alterações pigmentárias no pólo posterior (Figura 1B) com melhora da AV para 20/20 no OD e 20/60 no OE mantida até 3 meses.

\section{Paciente 3}

Gestante de 26 anos, negra, primigesta na $36^{a}$ semana de gestação, com feto único, com queixa de baixa acuidade visual em ambos os olhos e cefaléia holocraniana há três dias. Referia ganho acentuado de peso nas últimas semanas. Ao exame clínico apresentava PA de 170 x $130 \mathrm{mmHg}$, edema de MMII, e proteinúria de $24 \mathrm{~h}$ de $0,44 \mathrm{~g} / 1$.

Feito o diagnóstico de pré-eclâmpsia e realizado exame oftalmológico no leito, que revelou intenso estreitamento arteriolar, descolamento seroso na região inferior e macular em ambos os olhos e na região nasal do OD, além de lesões amareladas profundas, distribuídas no pólo posterior. Houve estabilização do quadro materno com melhora dos níveis pressóricos e da queixa de embaçamento visual com sulfato de magnésio e hidralazina, tendo sido indicada interrupção da gravidez por parto cesáreo.

Após três dias do parto a paciente apresentava ao exame oftalmológico acuidade visual de 20/200 no OD e 20/80 no OE, descolamento seroso na região inferior (das 3 às $7 \mathrm{~h}$ ), pregueamento da membrana limitante interna na região macular e persistência das lesões amareladas. $\mathrm{Na}$ $\mathrm{AF}$, estas lesões apresentaram hipofluorescência precoce por não perfusão da coróide, que nas fases tardias do exame foram tornando-se hiperfluorescentes por vazamento do corante.

Dez dias após o parto, a paciente apresentava acuidade visual de 20/40 em AO e no exame fundoscópico notava-se diminuição da extensão e aplanamento do descolamento seroso com atenuação das lesões profundas que já se apresentavam de coloração acinzentada e com alteração pigmentária reacional. Na AF mantinha as áreas de hipofluorescência sem pontos de vazamentos. 


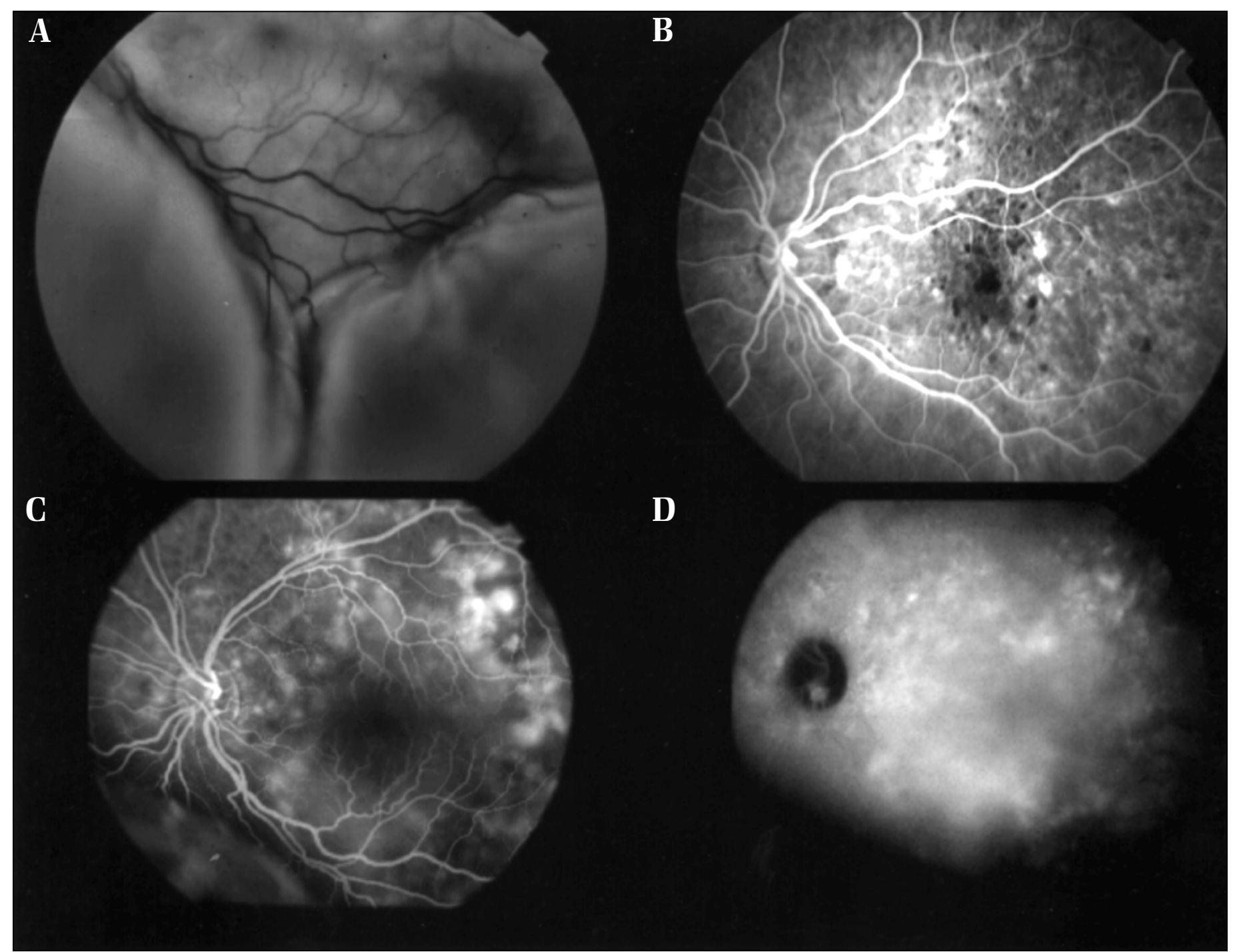

Fig. 1 - A: Retinografia colorida OE. Extensas bolsas periféricas de descolamento seroso da retina; B: Angiofluoresceinografia OE. Vários pontos de hiperfluorescência transmitida e hipofluorescência por bloqueio correspondendo à alterações pigmentárias no pólo posterior; $C$ : Angiofluoresceinografia $O E$. Múltiplos pontos hiperfluorescentes com vazamento e acúmulo do corante no espaço subretiniano na área de descolamento seroso no pólo posterior; D: Indocianinografia OE. Várias áreas hiperfluorescentes por vazamento e acúmulo do corante.

Oito meses após o parto, a paciente apresentava acuidade visual de 20/20 em AO e uma alteração pigmentária reacional residual com aspecto granular grosseiro.

\section{Paciente 4}

Gestante de 22 anos, branca, primigesta na $32^{\text {a }}$ semana de gestação, com queixa de diminuição súbita da visão em $\mathrm{AO}$, inicialmente no OE como uma mancha escura central no campo visual há 4 dias e progressivamente no OD com embaçamento visual e exotropia. A gestação evoluiu sem intercorrências até o início destes sintomas. A PA era de $150 \times 100 \mathrm{mmHg}$ e havia discreto edema de MMII. No exame oftalmológico apresentava AV de 20/60 no OD e conta dedos a $50 \mathrm{~cm}$ no $\mathrm{OE}$, com oftalmoscopia evidenciando no pólo posterior descolamento seroso da retina com acometi- mento macular e várias áreas branco-amareladas em AO. Foi realizado o diagnóstico de pré-eclâmpsia e foram prescritos sulfato de magnésio e hidralazina, tendo sido interrompida a gestação 4 dias após por parto cesáreo com feto único vivo.

Um dia após o parto houve regressão parcial do descolamento seroso da retina, que ainda acometia ambas as máculas. As lesões mostravam-se leve escurecimento.

Um mês após, a AV era de 20/100 no OD e 20/80 no OE, havia diminuição da exotropia e aplanamento do descolamento no pólo posterior. A AF mostrou inúmeros pontos hiperfluorescentes por defeito em janela no pólo posterior e discreto vazamento com acúmulo tardio do corante no espaço subretiniano e na ICG-V pontos hiperfluorescentes por vazamento na área do descolamento. 
Após 3 meses ocorreu normalização da AV para 20/20, resolução total do descolamento seroso e a presença de alterações pigmentárias difusas no pólo posterior em AO.

\section{DISCUSSÃO}

As alterações oftalmológicas nas gestantes com DHEG são frequentes ${ }^{8}$, entretanto devido ao estado clínico geral comprometido e a atenção voltada ao recém-nascido, as queixas oculares são pouco valorizadas e muitos diagnósticos não são feitos. Além disso, os estudos angiográficos com a fluoresceína sódica são limitados pela restrição relativa de seu uso pelos riscos de teratogenicidade e passagem ao leite materno e embora não haja passagem da indocianina pela placenta e leite materno faltam estudos comprovando a segurança de seu uso durante a gravidez ${ }^{9}$.

O descolamento seroso da retina na pré-eclâmpsia foi descrito pela primeira vez por A. von Graefe em $1885{ }^{10}$. O mecanismo fisiopatológico dessa alteração não é totalmente conhecido e parece haver implicações retinianas e coroideanas no acúmulo de líquido sub-retiniano. Collier (1967) ${ }^{11}$ demonstrou experimentalmente em gatos o acometimento coroidiano na gênese do descolamento seroso, pela indução de isquemia por embolização dos vasos coróideos.

Os mecanismos de controle da regulação vascular são diferentes na retina e coróide. O sistema nervoso simpático desempenha papel regulador no tônus vascular da coróide, enquanto o retiniano ocorre por mecanismos auto-regulatórios locais ${ }^{12}$. Arana (1997) ${ }^{13}$ ao elucidar os achados angiofluoresceinográficos no trauma ocular contuso, propôs que os fenômenos de adaptação vasomotora da retina descritos na literatura também deveriam ocorrer nas artérias ciliares curtas posteriores, podendo, através desse mecanismo, explicar as alterações secundárias do epitélio pigmentado da retina na contusão retiniana semelhante ao que ocorreria na DHEG.

Na presença de um quadro hipertensivo agudo e grave, há vasoconstrição intensa na coróide, associada à formação de microtrombos de fibrina e plaquetas com conseqüentes áreas de isquemia e infartos na coróide. Estas lesões se apresentam oftalmoscopicamente como áreas branco-amareladas profundas ao nível do epitélio pigmentado da retina e são conhecidas como manchas de Elschnig ${ }^{14}$. Cronicamente elas tendem a apresentar aspecto granular grosseiro e de lesões hiperpigmentadas com halo hipopigmentado ${ }^{15}$. A manifestação angiofluoresceinográfica é a de hipoperfusão coróidea precoce com múltiplos pontos de vazamento e acúmulo tardio do corante ${ }^{16,17}$. Muitas vezes observa-se a presença de extensos descolamentos serosos em que a angiofluoresceinografia evidencia importante sofrimento da circulação coroideana na coriocapilar com envolvimento retiniano menos evidente corroborando o papel da coróide na fisiopatologia do descolamento seroso ${ }^{18}$.

Nos estudos angiofluoresceinográficos, todas as pacientes apresentaram hipofluorescência precoce por não perfusão da coróide que no decorrer do exame foram se tornando hiperfluorescentes por vazamento do corante nas fases tardias, caracterizando um padrão típico das lesões isquêmicas da coróide.

Com o uso e desenvolvimento da ICG-V obteve-se uma melhor compreensão do acometimento coróideo em várias patologias vasculares e inflamatórias. VALLURI e col.(1996) ${ }^{19}$ avaliando as alterações da circulação coroideana pela ICG-V na pré-eclâmpsia observou achados semelhantes ao das pacientes desse estudo com hipoperfusão coróidea precoce com impregnação de vasos pequenos e médios da coróide e múltiplos pontos de vazamento evidenciando sofrimento vascular coroidiano não só na coriocapilar. O envolvimento do epitélio pigmentado da retina parece ser secundário, bem como o acúmulo de líquido sub-retiniano.

O prognóstico visual nestas pacientes é favorável, visto que na maioria dos casos o descolamento seroso regride espontaneamente e a visão volta ao normal após algumas semanas do parto, embora eventualmente alterações residuais pigmentárias maculares possam levar à diminuição da visão ${ }^{5,20}$.

Os achados angiográficos na DHEG complementados com a ICG-V reforçam as evidências da descompensação e sofrimento vascular da coróide na fisiopatologia dessa doença, que foram sugeridos em estudos prévios pela angiofluoresceinografia.

\section{SUMMARY}

Purpose: To describe the ophthalmoscopic and videoangiographic findings with sodium fluorescein and indocyanine green $(I C G-V)$ in pregnancy toxemia $(P T)$.

Methods: Four female patients with PT underwent ophthalmologic evaluation and fluorescein angiography, complemented in two of them with digital indocyanine green videoangiography (ICG-V).

Results: All patients presented with bilateral serous retinal detachment that spontaneously regressed after arterial pressure stabilization. The fluorescein angiography disclosed early multiple patchy nonperfusion choroidal areas and hyperfluorescent spots with leakage and late pooling in the areas of serous retinal detachment. In the late lesions window defect hyperfluorescence and pigmentary blockage were observed. The ICG-V showed early choroidal nonperfusion and multiple hyperfluorescent spots with late areas of dye pooling.

Conclusions: $P T$ is generally associated with recovery of vision after resolution of the disease, although some vision loss may persist due to pigmentary changes in the macular region. The ICG-V better shows the choroidal involvement in the pathogenesis of the serous retinal detachment in PT, previously suggested by fluorescein angiographic studies.

Keywords: Pregnancy toxemia; Opththalmoscopy findings; Indocyanine green angiography; Fluorescein angiography. 


\section{REFERÊNCIAS BIBLIOGRÁFICAS}

1. Pipkin FB, Rubin PC. Preeclampsia - the "disease of theories". Br Med Bulletin 1994;50:381-96.

2. Fastenberg DM, Fetkenhour CL, Choromokos E, Shoch DE. Choroidal vascular changes in toxemia of pregnancy. Am J Ophthalmol 1980;89:362-8.

3. Fadigan AB Sealy DP, Schneider EF. Preeclampsia: progress and puzzle. Am Fam Phys 1994;49:849-56.

4. Beck RW, Gamel JW, Willcourt RJ, Berman G. Acute ischemic optic neuropathy in severe preeclampsia. Am J Ophthalmol 1980;90:342-6.

5. Dornan KJ, Mallek DR, Wittmann BK. The sequelae of serous retinal detachment in preeclampsia. Obstet Gynecol 1982;60:657-63.

6. Bjerknes T, Askvik J, Albrechtsen S, Skulstad SM, Dalaker K. Retinal detachment in association with preeclampsia and abruptio placentae. Eur J Obstet Gynecol Reprod Biol 1995;60:91-3.

7. Chatwani A, Oyer R, Wong S. Postpartum retinal detachment. A case report. J Reprod Med 1989;34:842-4.

8. Jaffe G Schatz H. Ocular manifestations of preeclampsia. Am J Ophthalmol 1987; 103:309-15.

9. Hope-Ross MW. ICG dye: Physical and pharmacologic properties. In: Yannuzzi LA, Flower RW, Slakter JS, ed. Indocyanine Green Angiography. St. Louis, Mosby Year Book, 1997;46-9.
10. Duke-Elder S, Dobree JH. Diseases of the retina. In: Stewart Duke-Elder, ed. System of Ophthalmology. St. Louis, Mosby 1967;10;775-814.

11. Collier RHL. Experimental embolic ischemia of the choroid. Arch Ophthalmol 1967;77:683-92.

12. Laties AM. Central retinal artery innervation. Arch Ophthalmol 1967;77:405-9.

13. Arana J. Diagnóstico por imagem em trauma ocular. In: Moreira Jr CA, Freitas D, Kikuta HS, ed. Trauma Ocular. Rio de Janeiro, Ed. Cultura Médica, 1997; 68-95.

14. Schmidt D, Loffler KU. Elschnig's spots as a sign of severe hypertension. Ophthalmologica 1993;206:24-8

15. Venecia G, Jampol LM. The eye in accelerated hypertension. Arch Ophthalmol 1984;102:68-73

16. Gitter KA, Houser BP, Sarin LK, Justice Jr J. Toxemia of pregnancy - an angiographic interpretation of fundus changes. Arch Ophthalmol 1968;80:449-53

17. Kenny GS, Cerasoli JR. Color fluorescein angiography in toxemia of pregnancy. Arch Ophthalmol 1972;87:383-8.

18. Ramos ARB, Zaniolo S, Avila SZ, Arana JA, Moreira Jr CA. Descolamento exsudativo da retina sem sinais de retinopatia hipertensiva severa na toxemia da gestação. Arq Bras Oftal 1994;57:383.

19. Valluri S, Adelberg DA, Curtis RS, Olk RJ. Diagnostic Indocyanine Green Angiography in Preeclampsia. Am J Ophthalmol 1996;122:672-7.

20. Bosco JAS. Spontaneous nontraumatic retinal detachment in pregnancy. Am J Obstet Gynecol 1961;82:208-12.

\section{Seminário Internacional de Córnea e Lentes de Contato 24 e 25 de março de 2000 - Gran Meliá São Paulo \\ COMISSÃo \\ Carlos Eduardo Leite Arieta \\ Milton Ruiz Alves \\ Newton Kara José \\ Nilo Holzchuh \\ PRESIDENTE DA COMISSÃO \\ CIENTÍFICA \\ Newton Kara José \\ PALESTRANTES \\ Bruce H. Koffler, Lexington, KY - USA \\ Oliver H. Dabezies, New Orleans, LO - USA \\ Susan M. Stenson, New York, NY - USA \\ Tomy Starck, San Antonio, TX - USA}

SIMPÓSIOS:

PRESBIOPIA

AMINIÓTICA,

ASTIGMATISMO NOVAS REFRACÁOO

LENTES DE CONTATO,

\section{CURSOS PARALELOS}

C-1 - FÓRUM DE LENTES DE CONTATO

C-5 - NOVOS EXAMES AUXILIARES EM

Coordenadores: Newton Kara José e Wilson A. Marchi Jr. Coordenadores: Rosane Silvestre de Castro e Eliana

C-2 - ADMINISTRACÃO DO CONSULTÓRIO

Coordenador: Carlos Eduardo Leite Arieta

Matuda

C-3 - EXCIMER LASER I E II

Excimer Laser I - Coordenadores: Milton Ruiz Alves e

C-6 - AUXILIAR DE OFTALMOLOGIA

Denise de Vuono Chinzon

Coordenadores: Claudia Assis Lima e lineu Binotti

Excimer Laser II (complicacões) - Coordenadores:

Hamilton Moreira e Denise de Vuono Chinzon

C-4 - ADAPTACÃO DE LENTES DE CONTATO

ESPECIAIS

Coordenadores: Adamo Lui Netto e Paulo Ricardo de

Oliveira

C-7 - BIOMICROSCOPIA DO SEGMENTO

ANTERIOR

Coordenador: Fernando Oréfice

WE T L A B S

WL-1 - REFRACÃO - SUDOP

Coordenadores: Nilo Holzchuh e Marilisa Nano Costa

WL-2 - LENTES DE CONTATO

Coordenador: Nilo Holzchuh

INFORMAC̄̃̃ES : JDE COMUNICAÇ̃̃O E EVENTOS

Alameda Santos, 1343 - ci. 304 - 01419-001, São Paulo - SP

Tel. 11-289-4301 / 251-5273 - Fax. 11- 288-8157

E-mail:_idecomev@uol.com.br 